\title{
PELATIHAN KADER SEHAT SEKS DI SMA 1 BUNUT KABUPATEN PELALAWAN
}

\author{
Liva Maita, Rika Andriyani, Rina Yulviana \\ STIKes Hang Tuah Pekanbaru
}

\begin{abstract}
Based on the survey results of the Indonesian Survey Institute 2010-2011, knowledge of adolescent sex and knowledge of reproductive health is still relatively low, knowledge of male adolescents is only $46.1 \%$ and knowledge of female adolescents is only around $43.1 \%$. From other data, it is known that only 55\% of adolescents know the pregnancy process correctly, 42\% know about HIV / AIDS and only 24\% know about STDs. The aim of the activity is to increase the knowledge and skills of adolescents regarding reproductive health and healthy sex cadres. The method used is one day training which includes training and counseling on reproductive health. To assess the success of the training, a practical assessment and distribution of reproductive health questionnaires were carried out. Based on the observations during the activity, it was obtained: The cadres showed very high attention to the material presented, the cadres showed positive reactions to the practice of BSE and the cadres actively asked about problems regarding reproductive health, drugs and smoking. It is suggested that the school can provide counseling or provide information to other students, which is carried out by Sex Health Cadres who have been given previous training.
\end{abstract}

Keywords: training, healthy sex cadres

\begin{abstract}
ABSTRAK
Berdasarkan hasil survey Lembaga Survei Indonesia 2010-2011, pengetahuan seks remaja dan pengetahuan tentang kesehatan reproduksi masih relatif rendah, pengetahuan remaja laki-laki hanya $46,1 \%$ dan pengetahuan remaja perempuan hanya sekitar $43,1 \%$. Dari data lain diketahui hanya 55\% remaja yang mengetahui proses kehamilan dengan benar, $42 \%$ mengetahui tentang HIV/AIDS dan hanya $24 \%$ mengetahui tentang PMS. Tujuan kegiatan untuk meningkatkan pengetahuan dan keterampilan remaja mengenai kesehatan reproduksi dan kader sehat seks. Metode yang digunakan adalah pelatihan selama satu hari yang meliputi pelatihan dan penyuluhan mengenai kesehatan reproduksi. Untuk menilai keberhasilan pelatihan dilakukan penilaian praktek dan penyebaran kuesioner kesehatan reproduksi. Berdasarkan pengamatan selama kegiatan diperoleh : Para kader menunjukkan perhatian yang sangat tinggi terhadap materi yang disampaikan, para kader menunjukaan reaksi yang positif terhadap prakek SADARI dan Para kader aktif bertanya mengungkapkan masalah-masalah kesehatan reproduksi, Narkoba dan merokok. Disaranakan kepada pihak sekolah dapat memberikan penyuluhan atau memberikan informasi kepada siswi yang lain, dimana dilakukan oleh para Kader Sehat Seks yang telah diberikan pelatihan sebelumnya.
\end{abstract}

Kata kunci : Pelatihan, kader sehat seks 


\section{PENDAHULUAN}

Remaja adalah periode peralihan ke masa dewasa, mereka mulai mempersiapkan diri menuju kehidupan dewasa, termasuk dalam aspek seksualnya. Perilaku seksual adalah segala tingkah laku yang di dorong oleh hasrat seksual, baik dalam lawan jenisnya maupun dengan sesama jenis (Sarwono, 2011). Masa remaja disebut juga sebagai masa pubertas, berada pada rentang usia 11-20 tahun (Hockhenberry\&Wilson, 2009). Pada masa ini terjadi transmisi perkembangan antara periode kanakkanak dan dewasa (Papalia, Old \& Feldman, 2008), selain itu juga terjadi pematangan cepat secara fisik, kognitif, sosial dan emosional (Hockhenberry\&Wilson, 2009, Papalia, Old \& Feldman, 2008).

Kesehatan reproduksi adalah kesejahteraan fisik, mental dan sosial yang utuh dan bukan hanya tidak adanya penyakit atau kelemahan, dalam segala hal yang berhubungan dengan sistem reproduksi dan fungsi-fungsinya serta proses-prosesnya (Setiawan, 2010). Masalah seksualitas merupakan salah satu topik yang menarik untuk dibahas. Hal ini karena seksualitas adalah suatu hal yang sangat melekat pada diri manusia. Seksualitas termasuk kebutuhan dasar yang tidak bisa dihindari oleh makhluk hidup, karena dengan seks makhluk hidup dapat terus bertahan menjaga kelestarian keturunannya. Pada manusia, hasrat seksual mulai muncul dengan pubertas yaitu pada masa remaja. Remaja memiliki rasa ingin tahu yang tidak habis-habisnya mengenai misteri seks. Sebagian besar remaja merasa bingung dengan perubahan yang terjadi pada tubuhnya selama masa pubertas, dan terkadang informasi yang diterima mengenai hal ini tidak benar atau kurang lengkap terutama mengenai seks (Kusmiran, 2012).

Di Indonesia, Yayasan DKT yang merupakan perusahaan penghasil kondom melakukan survei melalui Sexual Behavior Survey Tahun 2011 di lima kota besar Indonesia menunjukkan bahwa $39 \%$ responden sudah pernah berhubungan seksual saat berusia 15-19 tahun, sisanya $61 \%$ berusia $20-25$ tahun. Perilaku seksual remaja ini terus mengalami peningkatan dari tahun ke tahun. Data terbaru dari Kementrian Kesehatan RI tahun 2013 yang merilis hasil penelitian di empat kota yakni Jakarta Pusat, Medan, Bandung, dan Surabaya, bahwa 55,9\% remaja sudah melakukan hubungan seksual sebelum menikah, bahkan $6,9 \%$ remaja perempuan melakukan aborsi. 
Kota Pekanbaru, Riau merupakan salah satu kota di Indonesia yang rawan terhadap perilaku seksual remaja. Hasil penelitian Dinata, Sabrian dan Wofesrt (2013) risalah satu SMA atau sederajat, Kota Pekanbaru menunjukkan sebanyak $2,7 \%$ remaja telah melakukan perilaku seksual dengan pasangannya. Tingginya prevalensi kejadian perilaku seksual remaja dan dampak berbahaya yang diakibatkan, berkaitan erat dengan faktor yang mempengaruhinya.

Berdasarkan hasil penelitian yang dilakukan oleh Dewi, Sahar dan Gayatri (2012) bahwa teman sebaya sangat signifikan mempengaruhi perilaku seksual remaja. Selain teman sebaya, perkembangan teknologi dan arus globalisasi melalui internet yang sangat mudah di akses remaja juga turut berkontribusi mempertinggi terjadinya perilaku seksual pada remaja.

Survei awal peneliti salah satu SMA sederajat menyatakan bahwa 33\% pihak sekolah menyatakan pernah dilakukan pengeluaran siswa akibat kehamilan, 33\% sekolah pernah mendapatkan siswanya berciuman di lingkungan sekolah dan $100 \%$ pelaksanaan per konselor sudah mati suri sejak 1-2 tahun yang lalu.
Berdasarkan hasil survey

Lembaga Survei Indonesia 2010-2011, pengetahuan seks remaja Indonesia masih relatif rendah, pengetahuan remaja lakilaki hanya $46,1 \%$ dan pengetahuan remaja perempuan hanya sekitar $43,1 \%$. Dari data lain diketahui hanya 55\% remaja yang mengetahui proses kehamilan dengan benar, $42 \%$ mengetahui tentang HIV/AIDS dan hanya $24 \%$ mengetahui tentang PMS.

\section{Perumusan Masalah}

Ketidak tahuan remaja mengenai kesehatan reproduksi dan tidak adanya kader sehat seks di sekolah

\section{Tujuan Kegiatan}

Tujuan Kegiatan adalah untuk meningkatkan pengetahuan dan keterampilan remaja mengenai kesehatan reproduksi dan kader sehat seks

\section{Metode Kegiatan}

Kegiatan ini dilaksakanakan pada tanggal 19 Januari 2017 di SMA Bunut Kab. Pelalawan yang diikuti oleh 11 orang calon kader sehat seks. Pengabdian ini dilakukan dengan cara memberikan pelatihan dan penyuluhan mengenai kesehatan reproduksi. Siswa/siswi akan dibekali materi selama satu hari yang diawali dengan penyebaran kuesioner kesehatan reproduksi kepada calon kader 
yang bertujuan untuk mengetahui pengetahuan siswa/wi. Untuk menilai keberhasilan pelatihan dilakukan penilaian praktek dan penyebaran kuesioner kesehatan reproduksi.

\section{Hasil}

Bedasarkan hasil pengamatan selama kegiatan pengabdian kepada masyrakat berlangsung, diperoleh beberapa hasil yang postif diantaranya adalah :

a. Para kader menunjukkan perhatian yang sangat tinggi terhadap materi yang disampaikan

b. Para kader menunjukaan reaksi yang positif terhadap prakek SADARI

c. Para kader aktif bertanya mengungkapkan masalah-masalah kesehatan reproduksi, Narkoba dan merokok.

Kegiatan penyuluhan dan pelatihan Kader Sehat Seks mengenai SADARI, menstruasi, narkoba dan rokok dilaksanakan di SMA 1 Bunut Balam Merah berjalan dengan baik dan sesuai rencana

\section{Kesimpulan}

Dari kegiatan pengabdian pada siswa ini dapat disimpulkan bahwa :

1. Pengetahuan anggota Kader Sehat Seks mengenai kesehatan reproduksi,
SADARI, mestruasi, narkoba dan rokok meningkat.

2. Anggota Kader Sehat Seks dapat memberikan informasi mengenai kesehatan reproduksi, SADARI, menstruasi, narkoba dan rokok kepada siswa lain.

3. Para anggota Kader Sehat Seks dapat mempraktekkan cara SADARI dengan benar.

\section{Saran}

Berdasarkan kepada hasil yang di peroleh maka dapat disaranakan sebagai berikut :

1. Mengadakan pelatihan kembali dengan materi yang lebih lengkap

2. Kepada pihak sekolah agar dapat mengadakan penyuluhan atau memberikan informasi kepada siswi yang lain, dimana dilakukan oleh para Kader Sehat Seks yang telah diberikan pelatihan sebelumnya.

\section{Daftar Pustaka}

Dewi, Ari Pritiani, dkk. 2015. Jurnal kesehatan soedirman the soedirman journal of nursing), volume 10, No. 3, November 2015.Google Scholar: http//googlescholar.co.id 
Efendy, Ferry dan Makhfudli. 2009.

Keperawatan

Kesehatan

Komunitas Teori dan Praktik

Dalam Keperawatan. Jakarta:

Salemba Medika

Hasanah,

Oswati

dan

Misrawati.2013.Analisa

Kesehatan Reproduksi Remaja

Perempuan Usia Early

Adolescence Di Pekanbaru.
NERS

JURNAL
KEPERAWATAN volume 9, No

1 Maret 2013. Google

Scholar:http//googlescholar.co.id

Marmi, 2014. Kesehatan Reproduksi.

Yogyakarta: Pustaka Pelajar

Setiawan, Ari dan Nugroho Taufan. 2010. Kesehatan Wanita, Gender Dan

Permasalahannya.

Yogyakarta: Nuha Medika 